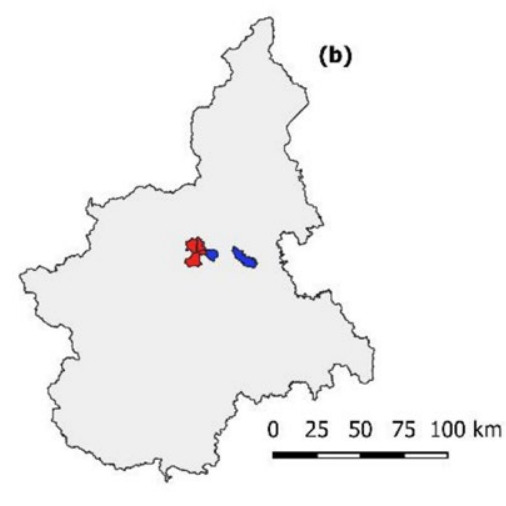

Earth \& Environment | E Borgogno-Mondino, A Borgia \& C Cigolini

\section{The TO-10 site in NW Italy is unsuitable for hosting the national nuclear waste repository}

The storage and disposal of radioactive waste is an issue of global concern. Italy has recently started the procedure of identifying suitable sites for its national repository of low- and medium-activity nuclear waste. This task was assigned to state-owned company, Sogin SPA, which recently published a national map of potentially suitable areas. 67 sites were identified, including TO-10, in Northwest Italy. However, researchers E Borgogno-Mondino and C Cigolini at the University of Torino, and A Borgia at European site is entirly uns Research Agency (EDRA), demonstrate that the TO-10 site is entiry unich of the superficial sedimentary units, a highly vulnerable and superficial groundwater table, and inadequate safety buffer zones around local settlements and the Torino metropolitan area.

Pariety of sectors, including energy production, medicine, industry, and agriculture. Given the risks to human health and the environment, radioactive materials are strictly controlled, with regulatory guidelines for their production use, transport, and disposal. The grues chane. The intesal are a

Atomic Energy Agency (IAEA) has established international Radioactive Waste (RW) safety standards for nearsurface disposal', specifically intend for disposal of low-level radioactive materials. Among them, the procedure for selecting waste repositories includ four steps: a) conceptualisation and genera site design; b) potential site based on environmental and sociopolitical factors (eg, land use, transport infrastructure, demographics, local and d) final site selection

Recently, Italy has started the procedure of identifying suitable sites for hosting its national RW repository A stateowned company, Sogin SPA (Sogin), has proposed a map (called CNAPI) areas to host the repository. The Sogin the criteria as defined in the Technical Guide no 29 edited by the Italian Institute for Nuclear Safety and Radio Protection introduced several 'exclusion criteria' (EC) for rejecting unsuitable sites, and in-depth investigation to technically chis nertise potenta' stes. However,

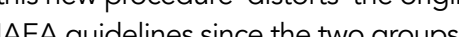
positioning 67 potentially suitable selection procedure takes into accoun (ISIN, 2014). Subsequently, ISPRA other 'investigation criteria' (IC) allowing

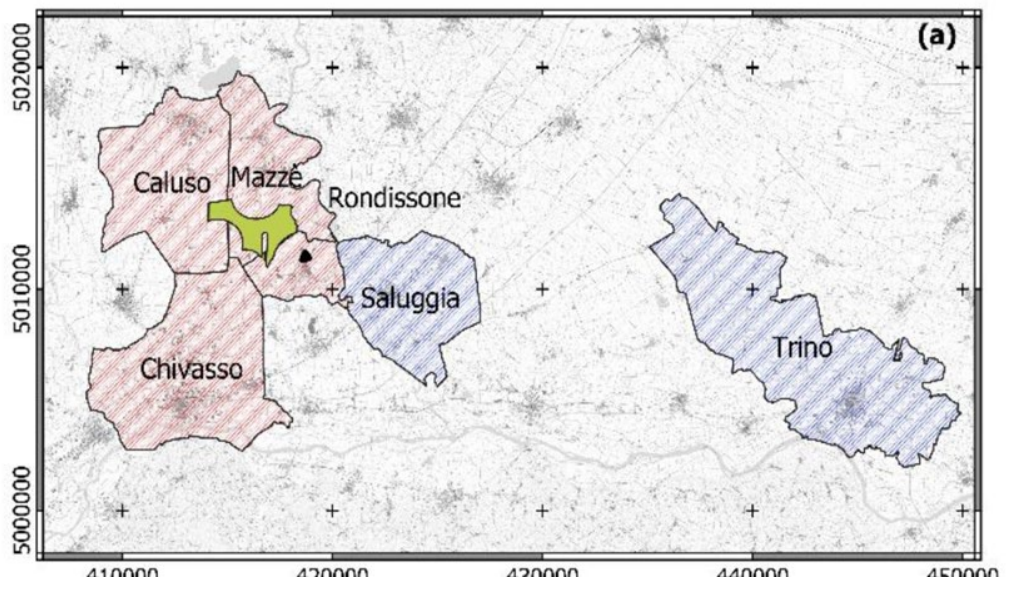

Figure 1. The location of the area TO-10 (green) within the Piemonte Region, NW Italy. Local administrative

of criteria may roughly overlap and interfere, putting the reliability of CNA into question.

Enrico Borgogno-Mondino and Corrado Cigolini of the University of (EDRA), investigated the TO-10 (Figure 1) for hosing the n-to a deposit for radioactive wastes The researchers considered the following issues: 1) geological, geomorphologica, hydrogeological details and characteristics of soils and sediments, which may allow radionuclide transfer into the biosphere; 3) protection and preservation of the area and its cultural heritage; 4) distance of the epository from man-made infrastructures and human activities, 5) distance from underground natural resources; and 6 ) protection from extreme environmenta and weather conditions.

The Italian national repository plan put forward by Sogin will host low However, Sogin states that the wast. Torino, and Andrea Borgia at European and hydraulic features of the area; 2)

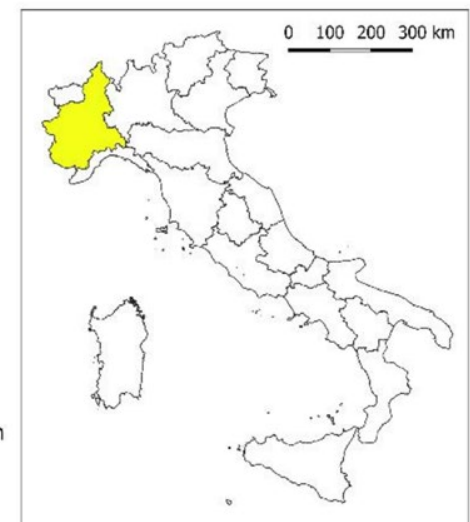

strictly satisfy specific IAEA guidelines Radioactive Waste ${ }^{\prime}$ ) thacti timpose the presence of at least an effective geological barrier. In their work, the University of Torino and EDRA researchers demonstrate that in the case of the TO-10 site, this barrier is totally absent, making storage of even low-level waste a significant risk.

\section{GEOLOGY AND TECTONICS} East of the city of Torino, the Po plain sits between the Alpine chain and the Torin and Monferrato hills, and represents the northern front of the Apennines in Northwest Italy. The main tectonic units in this sector of Piedmont are Al Apennine front, juxtaposed to the below the so gat un that converge Here plio-quaternary marine, glaciat and fluvio-glacial massive sediments covered by late pleistocene holocene alluvial sediments. This sector of the plain is crosscut by subsidiany rivers and springs, which converge into the Po river and reveal a unique geomorphological and hydrogeological scenario. Extended recharge zones, located at the foothills of the Alps and related moraines, feed the deep aquifers that represent fundamental water resources for huma consumption and agricultural uses.

The TO-10 area fully meets the exclusion criterion CE2: 'an area characterised by a high potential seismicity".
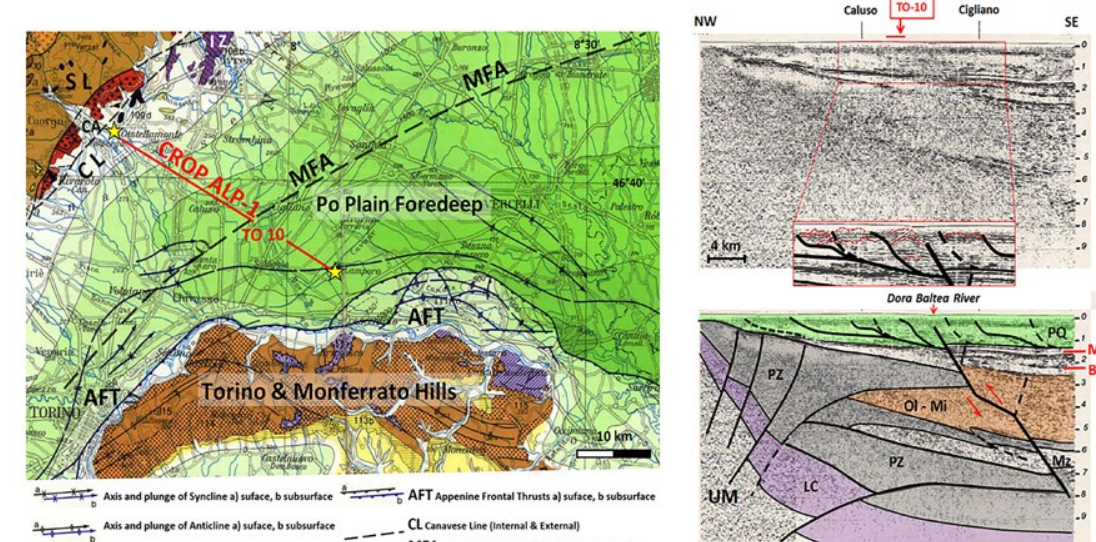

Figure 2. Left: subset of the structural model of ttaly by CNR. The CROP ALP-1 seismic profile is shown in

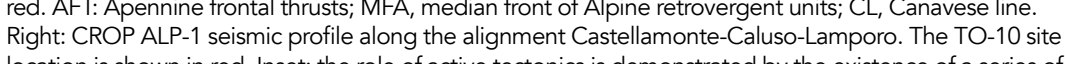

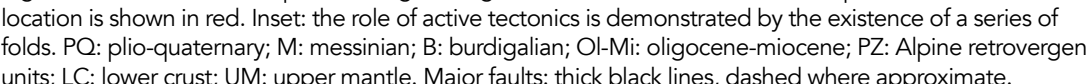

IAEA specific safety guide no SSG-29, 2014 

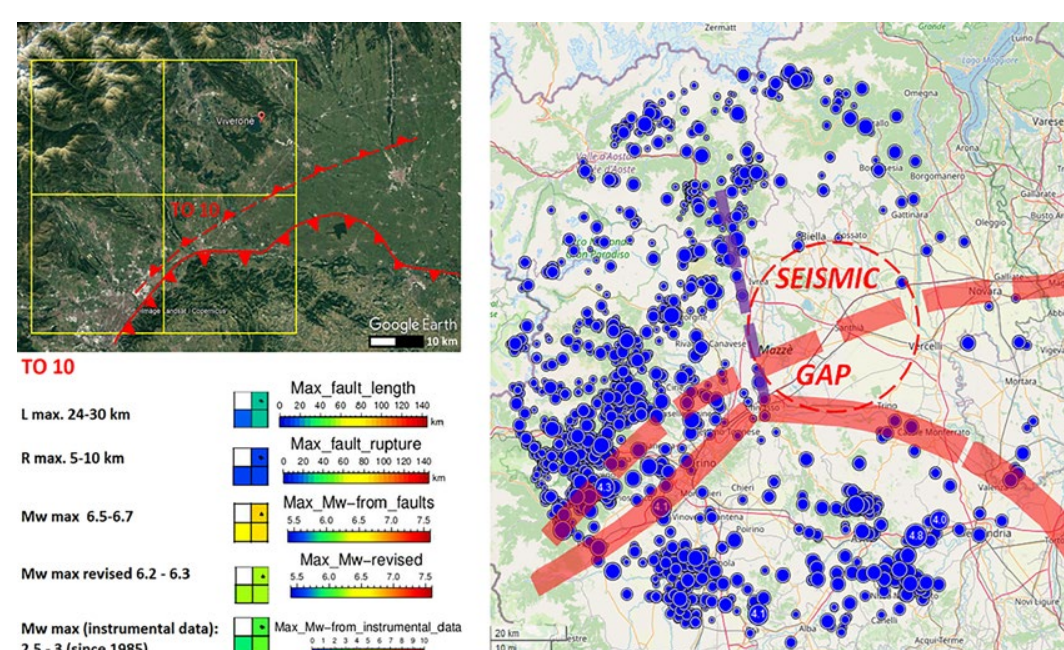

Igure 3. Left: $25 \times 25 \mathrm{~km}$ quadrants of the 'map of the maximum expected magnitude on

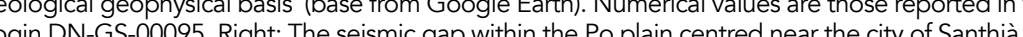
Earthquake data (ML $>$ ) are from the ISIDE-INGV catalogue. The traces of the Apennine frontal
thrusts (southern continuous red line, according to DISS database) and the median front of Alpine

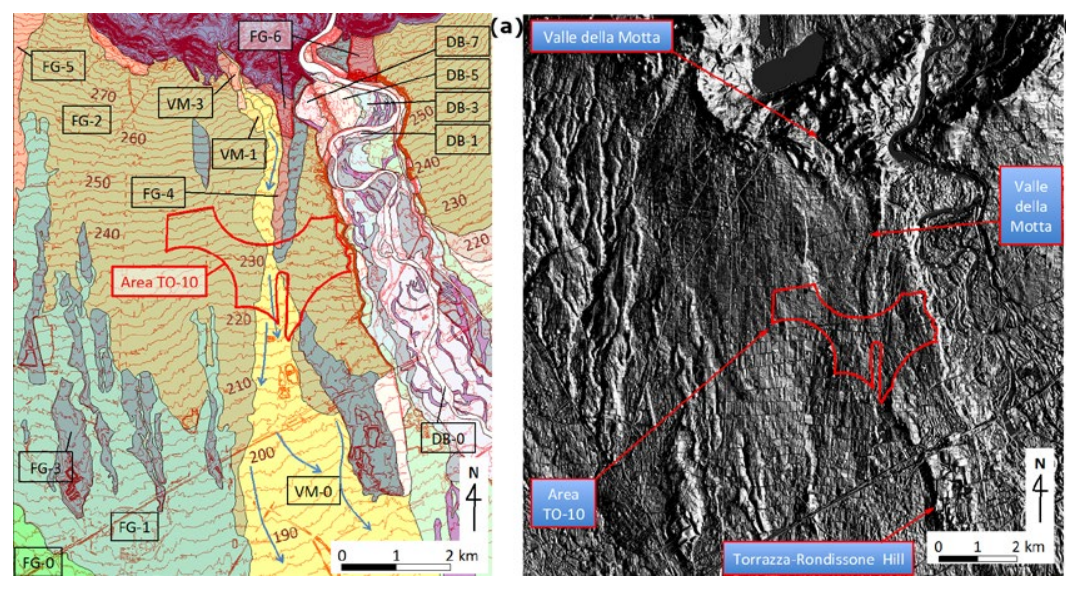

Figure 4. Left: Map of local terraces along the Dora Baltea River cañon: DB-1 (youngest) to DB-7 (oldest).
DB-0 is the active riverbed. Older fluvio-glacial plane terraces are indicated with FG-1 (youngest) to FG-6

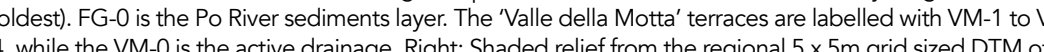
O-10 area. A set of terraces can be recognised in the glacio-fluvial sediments. The Dora Baltea cañon cus

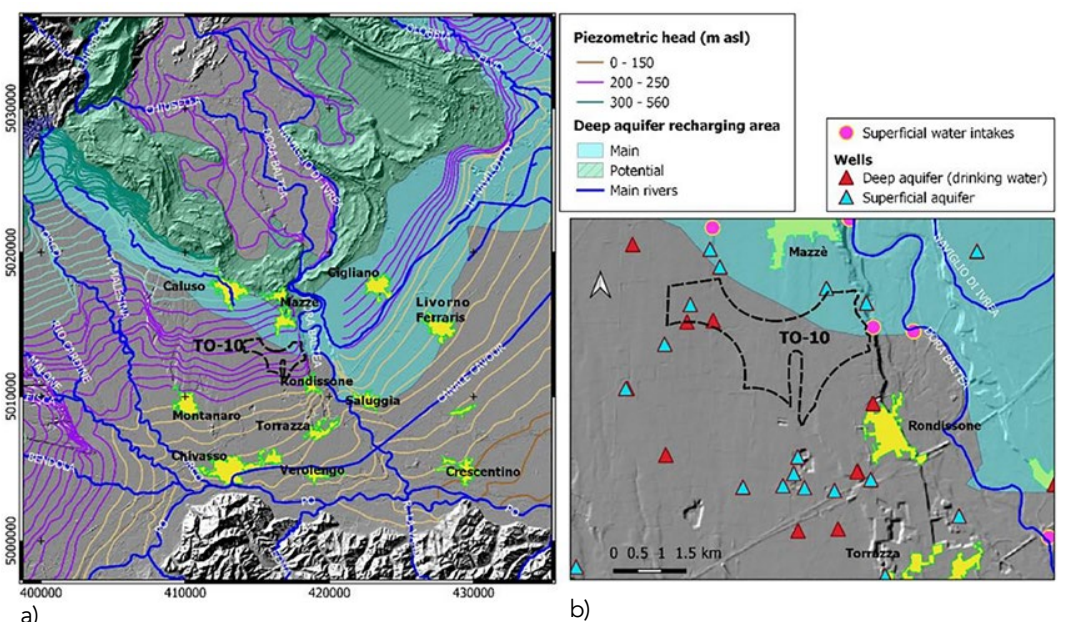
Figure 5. a Hydrogeological sketch of the TO-10 site and itis surroundings. Contour lines of
the water table. Light blue areas
with eport the recharge areas. b) Detalis of the TO-10 area and its surroundings the water table. Light blue areas reports
withnearsurface and deep wells
The CROP ALP-1 seismic profile crossFigure 2. Its andyis is shown in the stratigraphic setting (geological formations) and related faults Notably,

a major Apennine thrust fault (clearly visible below the Dora Baltea River) displaces the southern Alpine basement units (as far as $8 \mathrm{~km}$ deep) as well as the overlaying tertiary and quaternary sediments. The role of active tectonics is also demonstrated by the existence of a series of folds (such as fault-propagation and fault-bend folds), as shown in inset, Figure 2. Importantly, this configuration satisfies the EC3 exclusion criterion: 'are affected by faulting phenomena:

Potential seismicity of this sector of the o plain is obtained on the basis of a University of Rode (Sogin repor DN-

GS-00095) with the maximum expected mitude potentially occuring wected the single quadrants $25 \times 25 \mathrm{~km}$, Figure 3). The maximum magnitude expected for the TO-10 sector can theoretically reach magnitude of 6.5-6.7, which is typical of some historical earthquakes in this region (eg, the 1117 Verona, 1222 Brescia, and 2012 Emilia earthquakes). Thus, estimated ground peak accelerations occurring within a radius of $5 \mathrm{~km}$ are well above $0.25 \mathrm{~g}$.

Furthermore, the presence of a 'seismic gap, (obtained from the ISIDE-INGV public catalogue: iside.rm.ingvitt) indicates that this sector is considered to energy is not regularly disspe the seismic is in neighbouring areas characterised by greater seismicity, Figure 3). Therefore, the accumulation of elastic deformation can favour the breaking of significant portions of the crust and trigger earthquakes of considerable magnitude. On this basis, the TO-10 area fully meets exclusion criterion CE2: 'an area characterised by a high potential seismicity'.

\section{GEOMORPHOLOGY}

\section{AND HYDRAULIC HAZARDS}

Along the Dora Baltea River, the relief of the geological landforms (relict luvial forms) shows a series of terraces characterised by paleo meanders, These terraces describe successure ord of permanence of the river at higher altitudes compared to current ones. Th the Mazze mounine is charterised four 'entrenched meanders' that testify the ongoing tectonic uplift of the area (almost $1.5 \mathrm{~mm} /$ yearl). The presence of the 'Valle della Motta' active drainage since the pleistocene-holocen shows that the TO-10 area is highly vulnerable from a hydrogeological poin of view. In fact, the Piemonte region classified the southern sector of this drainage at high-risk of periodic flooding with return times varying between 25 and 50 years. Moreover, the nature and the geometry of the sedimentary cover, as well as the high hydraulic conductivity (10.-3 $\left.-10^{-5} \mathrm{~m} / \mathrm{s}\right)$ exclude the presence of a 'geological barier' to the escape standards require. Consequet high and/or extreme hydrogeological vulnerability of this are of the Po plain was demonstrated in 2005, through a cooperative research study by the Torino Polytechnical Institute in collaboration with Sogin. In conclusion, the TO-10 rea is remarkably vulnerable from a hydrogeological and alluvial point of view, falling under the EC4 and EC5 exclusion criteria.

\section{HYDROGEOLOGY AS DETECTABLE} BY OPEN PUBLIC DATA

The ISPRA exclusion criterion EC10 relates to the piezometric levels of superficial groundwater. This criterion is applicab compromise the degree of isolation of

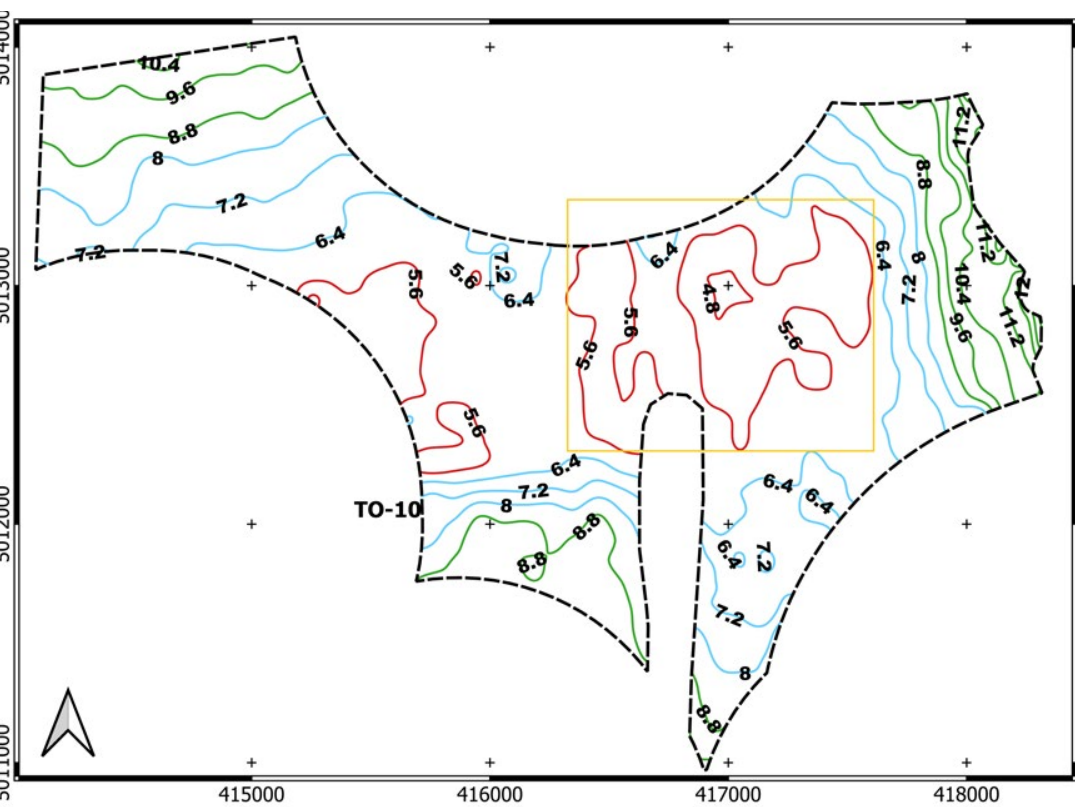

Figure 6. Geometry of the groundwater level below the surface (in metres) within the TO-10 site.

In addition to the biogas plant, three

high-voltage power lines and a gas pipeline run across the area, presenting significant potential for a major incident.

repository by interfering with its basement A detailed analysis of these data (Figure and foundations, enhancing the transfer of $\mathrm{J}$ ) shows that. a) the site partially lays in radionulldes towards the biosphere. The the recharging area of the deep aquifer approach taken by the researchers took (NE part of the site); b) a system of wells is present in the area. In particular, eight the pell deper-aquifer wells (some of them feeding the presence of recharge zones supplying drinking water) within or close supply drinking water (open data source: agricultural activities highly exposed to Regione Piemonte geoportal). source: enriroural actives highlyexpod to
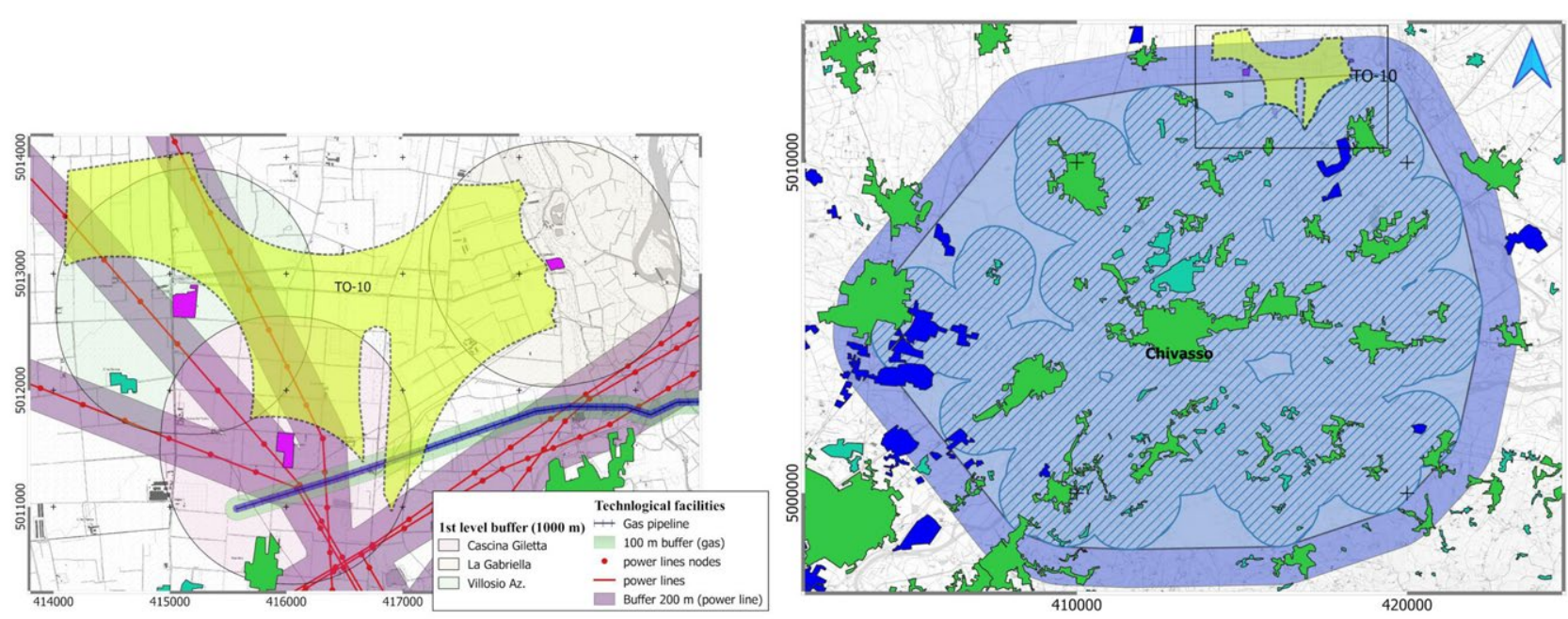

Figure 7. Left: First-level buffers (circular, 1km radius) around the three set
Right: second-l-evel buffer ('local urbanism') of the Chivasso municipality. 


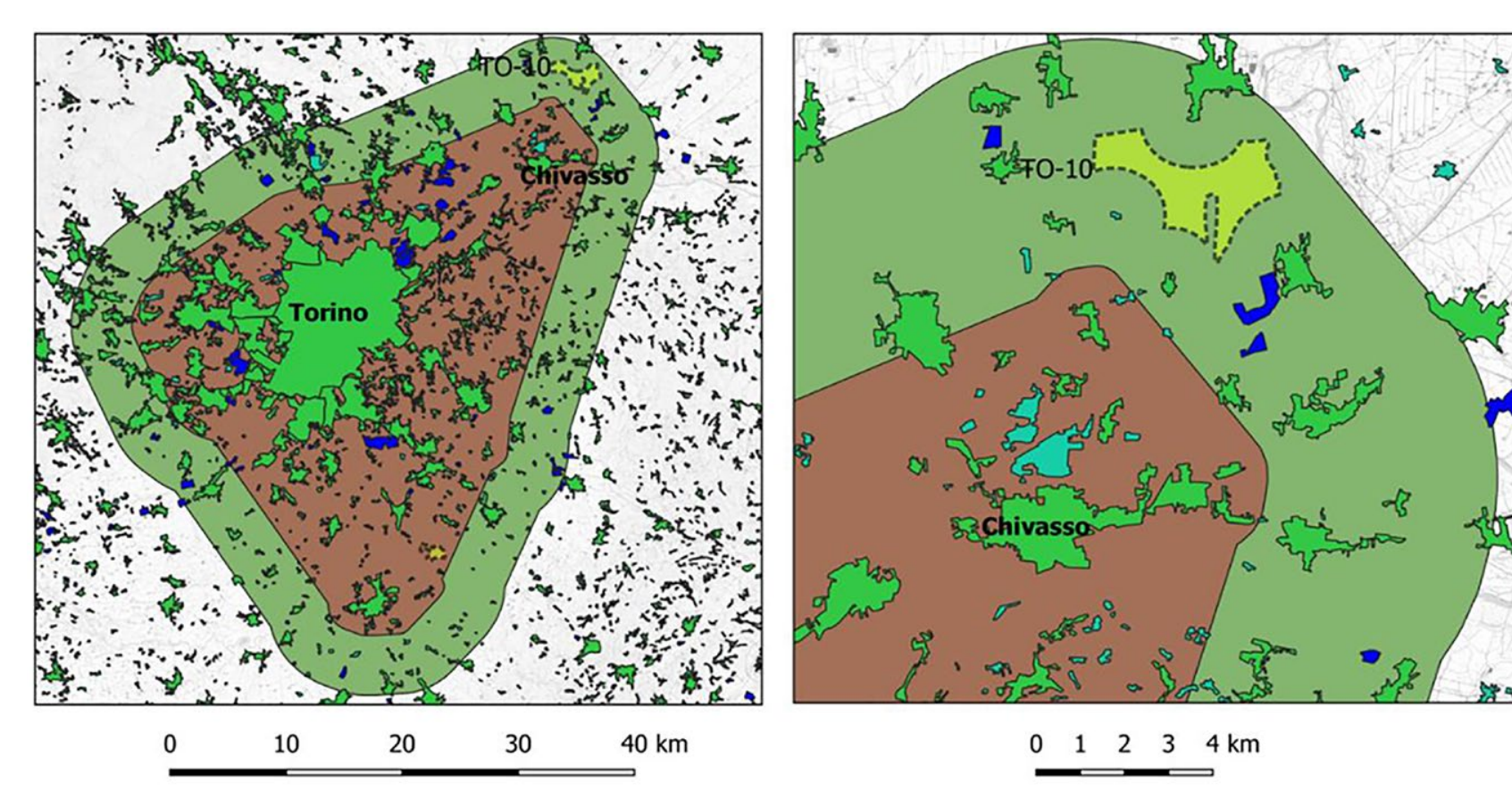

Figure 8. Left: Saferty buffer of the Turin metropolitan area (third-level of analysis) from the maps provided by Sogin, overall view. Right: details of the NE sector of
the buffer zone, which includes the TO-10 area. repository The whole scenario becomes critical if Takage from the repositon table and river. A possible contamination terrain model data, the depth of the were to contaminate the 'downstream' wells and the nearby Dora Baltea water front of radioactive nuclides may also easily reach the Po River, exponentially increasing the nuclear hazard within the whole basin

By cross-checking the available 'piezometric head' models with digital superficial water table was obtained for the TO10 site. Its depth ranges between $11 \mathrm{~m}(\mathrm{~N}) \mathrm{m}$

'distance from inhabited centres' is organised into three levels: 1) inhabited centres and nuclei; 2) local urban areas; 3) metropolitan areas. Site mapping is based on ordinary geographical information ISTAT maps which are out of date (last updated in 2011). During the selection of the 67 sites included in the CNAPI, Sog applied only the first level of analysis (distance from inhabited centres) by considering a 'buffer safety zone' of $1 \mathrm{~km}$

(DNGS00198 and DNGS00227), Figure 8 The applied procedure took into consideration all those settlements (and their first-level buffers) falling within a Chivasso. It was found that the resulting potential buffer highly impacts on the TO-10 area and excludes more than $90 \%$ of its surface.

The researchers also performed a thirdapplied the buffers
mapped by Sogin,

The researchers demonstrate $\quad \begin{aligned} & \text { mapped by Sogin, } \\ & \text { providing them with }\end{aligned}$ that the TO-10 site is unfit to host the vectormaprate talian national nuclear waste repository (shapefile). Here, the (central/eastern sector). Taking into account the

measured seasonal changes within the Vercelli Plain (ust $1 \mathrm{~km}$ east of TO-10) which fluctuate by $\pm 4 \mathrm{~m}$, the water table can easily reach the surface (as reported by several local farmers) or interact with is particularly critical for the safety of the local and surounding environment and communities. Thus, according to ECIO the TO-10 area should definitely have bee excluded as a potential sile. In addition, C14 criteria are also satisfied due to the

The procedure implemented by Sogin Sogin found that the TO-10 site includes two 'inhabited nuclei' and one biogas production plant (NW side) whose buffers exclude about $80 \%$ of the total surface of the TO-10 area. In addition to the biogas plant, three high-voltage power lines and a gas pipeline run across the area, incident (EC15), Figure 7.

To test the effects of a higher-level analyses, the researchers applied the second-level (namely,'Iocal urbanism ' to the nearby municipality of Chivass processed according to Sogta were level analysis, involving the metropolitan the basement of the repository. This fact presence of relevant hydric resources. pository. TO-10 site is totally

'buffer zone' of the Torino metropolitan area, therefore should undoubtedly be excluded as a potential site for hosting the repositony

In conclusion, the researchers demonstrate that the TO-10 site is waste repository. These findings were not unexpected. earlier investigations by ENEA (2003) and the Polytechnic of Torino, in cooperation with Sogin (2005), excluded TO-10 as a possible target site. th is therefore unclear on what basis this CNAPI procedure.

\section{Behind the Research}

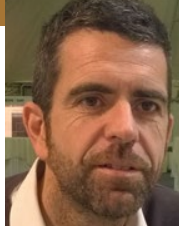

Professor Enrico
Borgogno-
Mondino

Professor

Andrea

Borgia

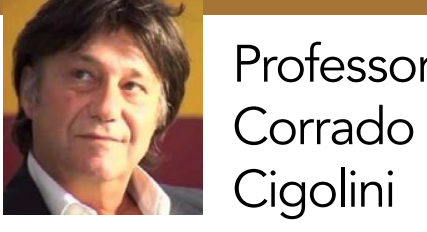

W: Geomatics and rural building - Department of Agricultural, Forest and Food Sciences - Università degli Studi di Torino (unito.it) Research Objectives

Enrico Borgogno-Mondino, Andrea Borgia, and Corrado Cigolini demonstrate the unsuitability of the TO-10 area, Northwest Italy, for hosting the national radioactive waste repository.

\section{Detail}

\section{Address}

Fept of Agriculture

Largo Braccini, 2- 10095 Grugliasco (TO)

Enrico Borgogno-Mondino is an

associate professor in geomatics at
the University of Torino. His PhD is in

geodesy and geomatics and MSc in

environmental engineering. He has

authored more than 100 scientific

is a member of the board of the Italian

Association of Remote Sensing, Presiden

\section{References}

Borgogno-Mondino, E, Borgia, A, Cigolini, C, (2021) the TO-10 Site (NW Italy). Land, 10, 932, doi.org/10.3390/ land10090932

ISPRA (2014) Guida Tecnica n 29 Criteri per La Localizzazione di un Impianto di Smaltimento Superficiale di Rifiuti Radioattiv isprambiente.govi.tfilies/nucleare/Guidatecrica29.pdf
isprat Civita, M, De Maio, M, Chiaravalli, F, Buonone, E, (2005) nell'ambito della Caratterizzazione Ambientale di un Sito ucleare, GEAM Torino: Colorno, Italy, 2005; 1-10, iris.polito sito_nucleare.pdf

ENEA (2003) Sistema Informativo Geografico per il sito del ENEA, Rome January 2003, 26, www archivionuclearecom files/studio-gsp3-sito-deposito-nazionale-2003.pdf. A complete database on the TO-10 area (in Italian) may be Vulnerabilit\%C3\%A0\%20dello F2\%80\%99acauifero\%20libero of the Scientific Council and board Scientific Associations for Territorial and

drea Borgia is a senior consultant, component thermal porous/fractured media flow on Earth and Mars, and University of Perugia. He has served Assessment Commission of the Italian Mnistry of Environment for 17 years. viewed international Journals.
Corrado Cigolini is a senior scientist and TO-10 area. Has been actively involved in teaching and research at the University field geology in complex tectonic settings, seismic and volcanic risk, geochemistry
of the radon progeny na dits monitoring, of the radon progeny and its monitoring,
and igneous petrology. He gained his the USA, Costa Rica, and Japan.

Collaborators

We acknowledge the contribution of the relationships among terraces along the Dora Baltea River.

Personal Response

Where is
in Italy?

II At this time radioactive wastes in taly are stored in power plants and research laboratories. Some high-activity wastes have been processed abroad, where they are
currently stored.

Do you think a suitable area can be identified to creat

II Nowadays this procedure is ongoing: we simply challenge the lack of adequate preliminary investigation potential site for hosting the national radioctive waste deposit. A feasible site should be explored in areas where the substratum is characterised by impermeable rocks (that warrant the presence of a reliable geological barrier be found within less populated regions subject to lower nvironmental pressure. 